\title{
FREQUENCY AND ANTIMICROBIAL SUSCEPTIBILITY PATTERN OF ISOLATES IN CENTRAL VENOUS CATHETER COLONIZATION.
}

1. BSc, MLT Student

Punjab Institute of Cardiology.

2. MBBS, M.Phil

Consultant Microbiology

Punjab Institute of Cardiology

3. MBBS, M.Phil

Professor Pathology

Rai Medical College, Sargodha.

4. MBBS, M.Phil

Consultant Hematologist

Punjab Institute of Cardiology.

Correspondence Address:

Dr. Nadia Aslam

House No. 107 A, Aslam Block,

Peer Muhhamad Colony, Sargodha. drnadia76@yahoo.com

Article received on:

30/10/2019

Accepted for publication:

04/01/2020

\begin{abstract}
Arooj Fatima ${ }^{1}$, Naima Mehdi ${ }^{2}$, Nadia Aslam ${ }^{3}$, Mahfooz ur Rahman ${ }^{4}$
ABSTRACT... Colonization of central venous catheters increases the risk of blood stream infections and is associated with increased morbidity, mortality and excess hospital costs. Objectives: To estimate frequency of central venous catheter colonization. Study Design: Cross Sectional study. Setting: Microbiology Laboratory of Punjab Institute of Cardiology, Lahore. Period: May 2018 to December 2018. Material and Methods: Total 116 specimens of central venous catheters were received in the laboratory and processed to isolate various organisms. Organisms were identified on the basis of colonial morphology, Gram staining and biochemical tests. Antimicrobial sensitivity testing was performed and results were recorded. Results: Out of total 116 specimens of central venous catheters, bacterial growth was obtained from $74.1 \%$ of central venous catheter tips. From 86 cultures yielding growth, 94 micro-organisms were isolated. The most frequent organisms isolated from central venous catheter tip culture in decreasing order of frequency were Coagulase negative staphylococci (29.8\%), Staphylococcus aureus (24.5\%), Candida species (23.4\%), Klebsiella species (12.8\%), and Acinetobacter spp. (4.3\%). Drug susceptibility pattern of isolates was recorded. Conclusion: Central venous catheters can get colonized and lead to catheter related infections. Implementation of prevention programs can result in decrease in colonization rate of catheters and thus Catheter related infections.
\end{abstract}

Key words: Antimicrobial Susceptibility Testing, Central Venous Catheters, Colonization, CRI (Catheter Related Infection), Frequency.

Article Citation: Fatima A, Mehdi N, Aslam N, Mahfooz ur Rehman. Frequency and antimicrobial susceptibility pattern of isolates in central venous catheter colonization. Professional Med J 2020; 27(9):1906-1910.

DOI: $10.29309 / \mathrm{TPMJ} / 2020.27 .09 .4307$

\section{INTRODUCTION}

Central venous catheter (CVC) is usually a long and thin tube like structure that can be inserted percutaneously to access large veins. ${ }^{1} \mathrm{CVCs}$ are often used in recent days for infusing drugs and for providing total parenteral nutrition. Venous catheter access can be used for hemodialysis, hemofiltration, and hemodiafiltration in patients with renal failure and hemodynamic monitoring in the critically ill patients. ${ }^{2}$

The CVCs use can lead to various complications which can be mechanical or infections. ${ }^{3}$ While inserting CVCs faulty technique can result in damage to blood vessels, trauma to adjacent nerves or development of pneumothorax and hemothorax. ${ }^{4,5}$ Patients with indwelling CVCs are at enhanced risk of developing various catheter related infections (CRI) such as localized insertion site infections, septic thrombophlebitis, catheter related blood stream infections (CRBSI), bacteremia, metastatic infections, sepsis and if not promptly treated can result in patient's death. ${ }^{6,7}$

Colonization of CVC tips and resultant healthcare associated bacteremia and septicemia can contribute towards enhanced patient morbidity and mortality. CRBSI is among most common causes of nosocomial bacteremia and is defined as the bacteremia originating from an indwelling intravenous catheter. CRBSI is a fatal and costly complication of CVC use. ${ }^{8}$ The relative risk for CRBSI is up to 64 times greater with indwelling CVCs than with peripheral venous catheters. ${ }^{8}$ Surfaces of the CVC develop a coating of plasma proteins especially fibrin immediately after being inserted. Organisms having special affinity for the 
proteins constituents of this sheath can adhere and reside in this protein sheath. This process results in colonization of CVCs. ${ }^{9}$

\section{AIMS AND OBJECTIVES}

To determine rate of central venous catheter colonization and antimicrobial drug susceptibility of organisms isolated from CVC tips.

\section{MATERIAL \& METHODS}

This cross sectional study was conducted at Punjab Institute of Cardiology (PIC), Lahore from May 2018 to December 2018 over a period of eight months. All CVC tips (2-inch segment of the catheter in sterile tube or container) received in Microbiology Laboratory were processed through consecutive sampling technique. During study period, a total number of 116 central venous catheter tips were received in microbiology laboratory and processed using Maki's semiquantitative roll plate method. ${ }^{10}$ With the help of sterile forceps, the catheter tip removed from transport tube were rolled back and forth on the surface of a blood agar plate. Culture plates were incubated at $37^{\circ} \mathrm{C}$ under aerobic conditions. Agar plates were examined after 24, 48 and 72 hours of incubation for microbial growth. CVC tip colonization was defined as colony count of $\geq 15 \mathrm{CFU} / \mathrm{ml}$ by semiquantitative technique. Organisms were further identified on the basis of colony morphology, gram staining and biochemical tests. Antibiotic susceptibility test was determined by disk diffusion technique and E. Test strips as recommended by Clinical Laboratory Standards Institute (CLSI). ${ }^{11}$ Statistical analysis was performed using SPSS version 16.0.

\section{RESULTS}

In this study, total 116 specimens of CVCs were received in the laboratory from different units of hospital. The mean age of patients was 50.90 years; the minimum age was 13 years as compared to maximum of 75 . Out of a total number of 116 patients, 94(81\%) were male and $22(19 \%)$ were female. Most of the specimens were received from patients admitted in intensive care unit (ICU). Out of 116 specimens, 81 (69.8\%) were from ICU, followed by cardiac surgery ward and rooms 17 (14.6\%), Cardiology ward 12
(10.3\%), CCU 03(2.6\%), Cardiac surgery Pre-Op ward $02(1.7 \%)$ and isolation ward $01(0.9 \%)$.

Bacterial growth was obtained from $74.1 \%$ $(n=86)$ CVC tips. From a total number of 86 CVC tips, 94 micro-organisms were isolated as from 78 CVC tips single organism was isolated while from 8 CVCs more than one isolate was cultured. Gram Positive bacteria were 53 (54.7\%) most frequent isolates from CVC tips followed by Gram negative bacteria 19(16.3\%) and Candida species 21(19.8\%). (Table-I)

\begin{tabular}{|l|c|c|}
\hline \multicolumn{1}{|c|}{ CVP Tip Colonizers } & Frequency & Percentage \\
\hline Gram-positive bacteria & 53 & $56.4 \%$ \\
\hline Gram-negative bacteria & 19 & $20.2 \%$ \\
\hline Candida species & 22 & $23.4 \%$ \\
\hline Total & 94 & $100 \%$ \\
\hline
\end{tabular}

Table-I. Showing frequencies of CVC tip colonizers

Out of 94 isolates, 28 (29.8\%) were CoNS (Coagulase Negative Staphylococci), 23 (24.5\%) Staphylococcus aureus, 2 (2.1\%) Enterococcus species, 12(12.8\%) Klebsiella species, 4 (4.3\%) Acinetobacter spp., 1(1.1\%) E. coli, 2 (2.1) Pseudomonas species and Candida 22 (23.4\%). (Figure-1)

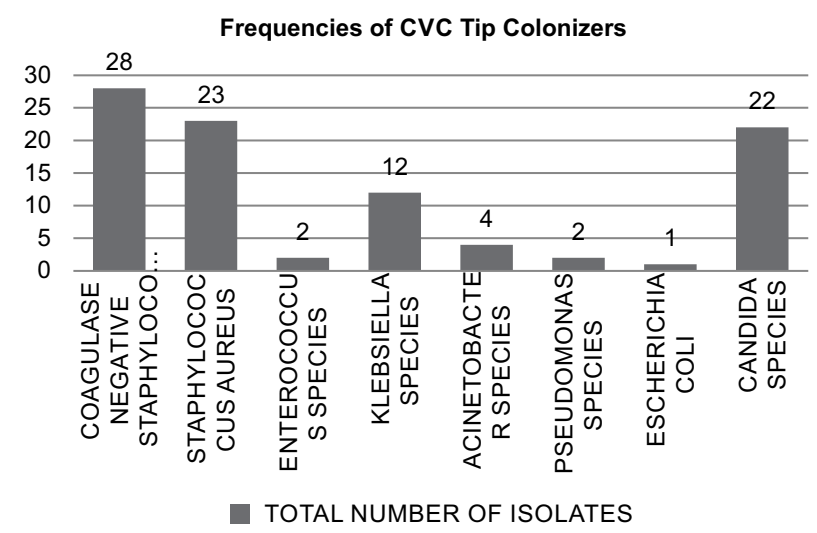

Figure-1. Showing frequencies of CVC tip colonizers

Drug susceptibility pattern of gram positive isolates to various commonly used drugs was determined and percentage of susceptible isolates is shown in Figure-2.

Drug susceptibility pattern of various gram negative isolates to various commonly used 
drugs was also determined and percentage of susceptible isolates is shown in Figure-3.

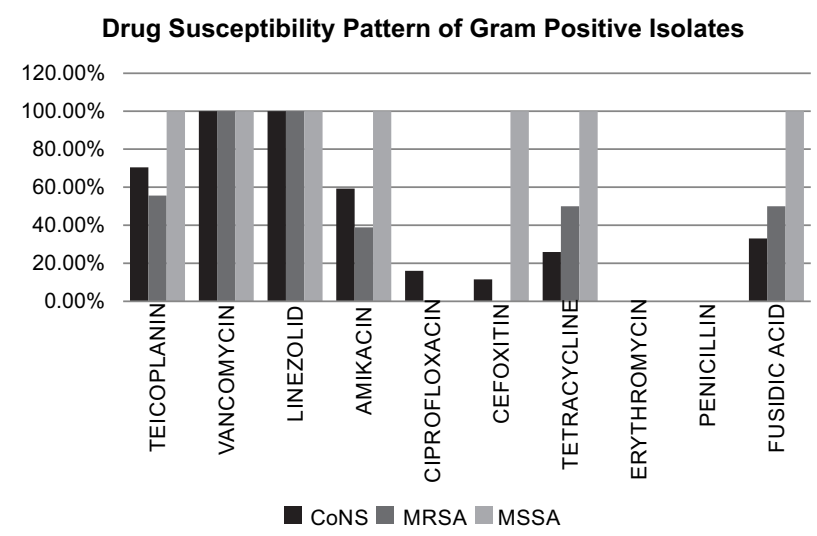

Figure-2. Showing drug susceptibility pattern of gram positive isolates

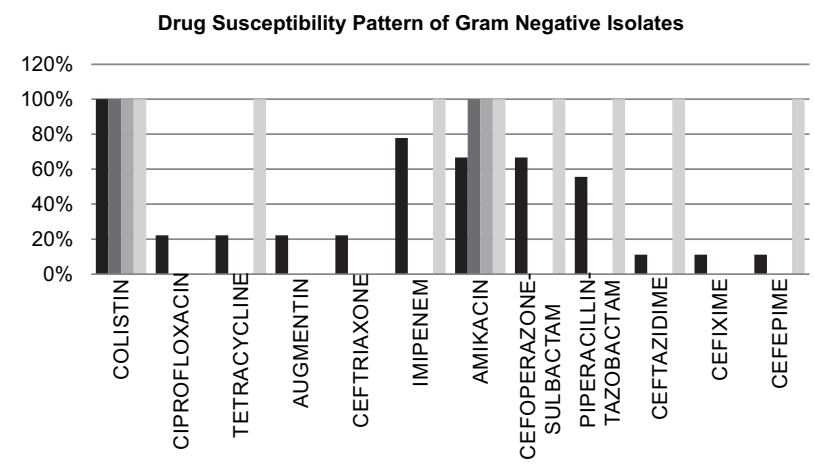

KLBSIELLA SP. $\square$ E. COLI $\square$ ACINETOBACTOR SP. PSEUDOMONAS SP.

Figure-3. Showing drug susceptibility patterns of gram negative isolates

\section{DISCUSSION}

This study was conducted to determine frequency of CVC colonization by various organisms and their drug susceptibility pattern. In this study, rate of CVP tip colonization was $74.1 \%$. Other studies show catheter tip colonization rate of $39.6 \%$, $18.3 \%, 15.0 \%$ and $24.5 \%$ respectively. $7,12,13,14$ Gram positive bacteria $(56.4 \%)$ were most frequent isolates followed by Candida species (23.4\%) and Gram negative bacteria $(20.2 \%)$ in this study. The most common organisms found in CVC culture were CoNS (52.8\%). A study by van Rooden CJ et al. documented CoNS to be responsible for causing nosocomial infection even when barrier precautionary measures while inserting CVCs are observed. CoNS can colonize CVC tips leading to localized or disseminated infections and this can result in early and premature removal of the
CVC. ${ }^{15}$

Various other bacteria can colonize skin at or around insertion site and can move along catheter tract to reach CVC tip thus making a portal for CRI. CRIs are usually caused by the micro-organisms which have ability to adhere and colonize catheters. ${ }^{15}$

In this study after CoNS, S.aureus (24.5\%), Candida sp.( $23.4 \%$ \%), Klebsiella sp. (12.8\%) and Acinetobacter sp. (4.3\%) were frequent organisms isolated from CVC tips. A study by Sapkota $\mathrm{J}$ et al. found Acenitobacter baumannii (29\%), S. aureus (19\%), Klebsiella pneumonia (14\%), CoNS (14\%) and Escherichia coli (5\%) as most frequent colonizers of CVCs. ${ }^{7}$ A study by Moretti EW reported S. epidermidis followed by $\mathrm{S}$. aureus as most frequent colonizers of CVCs. Other colonizers were Enterococcus faecalis, and Pseudomonas aeruginosa. Candida was found in less than $1 \%$ of cases. ${ }^{14}$

Colonization of CVC tips can lead to CRBSI which can be confirmed by isolating same organism from CVC tip and recovering the causative agent from blood culture or by using quantitative assays. ${ }^{16} \mathrm{~A}$ study by García-Vázquez et al. found Staphylococcus aureus and the coagulasenegative Staphylococci, Gram-negative bacilli, enterococci and yeast as leading causes of CRBSI. ${ }^{17}$ Bellemin et al. found CoNS (82.1\%) and $S$. aureus $(10.8 \%)$ as the most frequent cause of $\mathrm{CRI}{ }^{18}$ The findings suggest that most frequent colonizers of CVCs are most frequent organisms to cause catheter related infections.

\section{CONCLUSION}

In this study rate of colonization of CVC tip was quite high. This rate of CVC tip colonization must be decreased and resulting CRBSIs can be prevented. Implementation of aseptic techniques and preventive measures can reduce rate of CVC tip colonization. Emphasis should be placed on hand washing technique, skin cleaning with antiseptics, barrier precautions, change and early removal of catheters. Decrease in the rate of CVC tip colonization is mandatory and can possibly lead to decreased rate of complications. 
Copyright $\odot 04$ Jan, 2020.

\section{REFERENCES}

1. Mudan S, Giakoustidis A, Morrison D, et al. 1000 Portacath ${ }^{\circledR}$ placements by subclavian vein approach: Single surgeon experience. World J Surg 2015; 39(2): 328-34. doi: 10.1007/s00268-014-2802-x.

2. Sette P, Dorizz RM, Azzini AM. Vascular access: An historical perspective from Sir William Harvey to the 1956 Nobel Prize to Andre F. Cournand, Werner Forssman and Dickinson W. Richards. J Vasc Access. 2012;13(2):137-44 doi: 10.5301/jva.5000018.

3. Fang $\mathrm{F}$, Zhang $\mathrm{H}$, Yang W. An unusual peripherally inserted central catheter (PICC) fractured in vivo with embolization happened in a child: A case report. Case Reports in Clinical Medicine. 2015; 4(01),10-3 http:// dx.doi.org/10.4236/crcm.2015.41003.

4. Sadek M, Roger C, Bastide S, Jeannes P, Solecki K, Jong $A$, et al. The influence of arm positioning on ultrasonic visualization of the subclavian vein: An anatomical ultrasound study in healthy volunteers. Anesth Analg. 2016; 123(1):129-32 https://doi. org/10.1213/ANE.0000000000001327.

5. Ablordeppey EA, Drewry AM, Beyer AB, Theodoro DL, Fowler SA, Fuller BM, et al. Diagnostic accuracy of central venous catheter confirmation by bedside ultrasound versus chest radiography in critically ill patients: A systematic review and meta-analysis. Crit Care Med. 2017; 45(4):715-24. doi: 10.1097/ CCM.0000000000002188.

6. Silberzweig JE, Sacks D, Khorsandi AS, Bakal CW; Reporting standards for central venous access. J Vasc Interv Radiol. 2003; 14:S443-52. https://doi. org/10.1097/01.rvi.0000094617.61428.bc.

7. Sapkota J, Mishra B, Jha B, Sharma M. Bacteriological profile and their antimicrobial susceptibility pattern in central venous catheter tip culture. Journal of Pathology of Nepal. 2017, 7(1):1059-61. https://doi. org/10.3126/jpn.v7i1.16670.

8. Gahlot R, Nigam C, Kumar V, Yadav G, Anupurba S. Catheter related bloodstream infections. Int J Crit IIIn Inj Sci. 2014; 4:162-7. doi: 10.4103/2229-5151.134184.

9. Qamar M, Gillani SW, Sulaiman SAS. Skin preparation knowledge, attitudes and practices among the healthcare professionals in compliance with the World Health Organization (WHO) guidelines. Journal of Clinical and Diagnostic Research 2012; 6(6):1041-6.
10. Slobbe L, El Barzouhi A, Boersma E, Rijnders BJ. Comparison of the roll plate method to the sonication method to diagnose catheter colonization and bacteremia in patients with long-term tunneled catheters: A randomized prospective study. J. Clin. Microbiol. 2009; 47:885-8. https://dx.doi. org/10.1128\%2FJCM.00998-08.

11. Clinical and laboratory standards institute. Performance standards for antimicrobial susceptibility testing. 28th ed. CLSI supplement M100.2018 http://iacld.ir/DL/public/CLSI-2018M100-S28.pdf.

12. Pérez-Granda MJ GM, Cruces R, Barrio JM, Bouza E. Assessment of central venous catheters colonization using surveillance culture of withdrawn connectors and insertion site skin. Crit Care. 2016; 20: 32. doi: 10.1186/s13054-016-1201-0.

13. Perez-Granda MJ, Guembe M, Cruces R, Bouza E. Vascular catheter colonization: surveillance based on culture of needleless connectors. Crit Care. 2016; 20(1):166. doi: 10.1186/s13054-016-1334-1.

14. Moretti EW, Ofstead CL, Kristy RM, Wetzler HP. Impact of central venous catheter type and methods on catheter-related colonization and bacteraemia, JHosp Infect. 2005. 61, 139-145. https://pdfs.semanticscholar. org/5b67/924166b672780c8bc4bc9ef4449baca3b56c. pdf

15. Van Rooden CJ, Schippers EF, Guiot HF, Barge RM, Hovens MM, van der Meer FJ, et al. Prevention of coagulase-negative staphylococcal central venous catheter-related infection using urokinase rinses: A randomized double-blind controlled trial in patients with hematologic malignancies. J Clin Oncol. 2008; 26:428-33. doi: 10.1200/JCO.2007.11.7754.

16. Ullman AJ, Cooke ML, Gillies D, Marsh NM, Daud A, McGrail MR, et al. Optimal timing for intravascular administration set replacement. Cochrane Database Syst Rev. 2013; (9):CD003588 https://doi. org/10.1002/14651858.CD003588.pub3.

17. García-Vázquez E, Fernández-Rufete A, HernándezTorres A, Canteras M, Ruiz J, Gómez J. When is coagulase-negative Staphylococcus bacteraemia clinically significant? Scand. J. Infect. Dis.2013; 45:664 -71. http://dx.doi.org/10.3109/00365548.2013.7 97599.

18. Bellemin K, Voirin N, Bonfils M, Bouamari H, Vincent $A$, Valdeyron $M L$, et al. Catheter-related infections in neonatal intensive care units: A prospective multicentre surveillance. BMC Proc. 2011; 5(6): 07. https://dx.doi.org/10.1186\%2F1753-6561-5-S6-O7. 


\section{AUTHORSHIP AND CONTRIBUTION DECLARATION}

\begin{tabular}{|c|c|c|c|}
\hline Sr. \# & Author(s) Full Name & Contribution to the paper & Author(s) Signature \\
\hline 1 & Arooj Fatima & $\begin{array}{l}\text { Data collected and manuscript } \\
\text { writing. }\end{array}$ & \\
\hline 2 & Naima Mehdi & $\begin{array}{l}\text { Data processing, Statistical } \\
\text { analysis. }\end{array}$ & 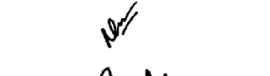 \\
\hline 3 & Nadia Aslam & $\begin{array}{l}\text { Compiled results, Manuscript } \\
\text { writing and editing of manuscript. }\end{array}$ & 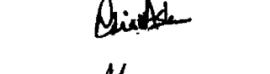 \\
\hline 4 & Mahfooz ur Rahman & Statistical analysis. & \\
\hline
\end{tabular}

